\title{
The pedagogical and multimedia designs of learning objects for schools
}

\author{
Margaret Haughey \\ University of Alberta \\ Bill Muirhead \\ University of Ontario Institute of Technology
}

\begin{abstract}
While much has been written about learning objects, the focus of discussion has been on standards, theoretical principles or post-secondary applications. Little has been published about the issues of the K-12 sector. From the literature, interactivity and scaffolding are the two pedagogical aspects considered crucial to learning object design. In multimedia design, writers have focused on engagement, persistence and success in simulation, gaming, narrative and experiential situations. Using these criteria we examined the pedagogical and multimedia design features in $35 \mathrm{~K}-10$ learning objects produced by The Le@rning Federation. Objects which met the learning and multimedia design criteria had clear objectives, multiple activities, high interactivity, learner choice and an extensive scaffolding interface behind the main design. Research on the use of learning objects by teachers and students is recommended as the next step.
\end{abstract}

\section{Introduction}

Learning objects lack a simple description (McGreal, 2004). Initially conceived as an effective and efficient means for providing virtual content that could be shared with others, how these two attributes are achieved remains contested by educators, designers and engineers. However, the pedagogical issues concerning learning objects have received considerable emphasis in the literature (Hannifin \& Hill, 2002; Merrill, 2002; McGee, 2003; Wiley, 2000). First, the debate surrounding various characteristics of learning objects sought to identify standards which placed constraints on the use of learning designs within objects (Wiley, 2000). Then the discussion focused on competing philosophies based on various educational theories and argued for and against context based learning objects (Merrill, 2002). More recently, the debate has been between those espousing efficiency, autonomy and simplicity, and those arguing for 
accountability, responsibility and complexity (Bannan-Ritland, Dabbagh \& Murphy, 2000; Hannafin \& Hill, 2002).

The definition of a learning object has become more complex as software engineers, instructional designers, content specialists, researchers, and educators have all sought to turn the notion of reusable digital resources into reality. As Wiley (2000) points out, its conceptualisation as a Lego block with the emphasis on its simplicity, regularity and reusability may have provided a false promise of the ease with which learning objects and their infrastructure could be designed. Software designers have grappled with the technical standards set out by The Institute of Electrical and Electronics Engineers (IEEE) of being reusable, accessible, interoperable, and durable. Instructional designers and educators have had to consider the competing characteristics of reusability versus localisation or specificity, and of instructivist and constructivist learning theories, as well as multimedia affordances.

These issues are not merely theoretical; rather they form the daily concerns of those involved in designing learning objects. They are of particular interest in the $\mathrm{K}-12$ sector where agencies and jurisdictions are held responsible for the quality of the learning resources and where appropriate pedagogical design is likely to be highly debated. In our research we sought to describe the pedagogical and multimedia designs used in learning objects developed and approved for use in schools.

\section{Pedagogical learning object design principles}

Instructional design and learning theories provide the pedagogical foundation for learning object design. Lajoie (2003) commented, "The uses of technology in education are boundless but are only as good as the principles that underlie their design, as well as the teachers who use them with a pedagogical purpose". We review recent learning object and then multimedia design principles which provide the basis for the criteria we used in reviewing selected learning objects.

\subsection{Learning object design principles}

The initial instructional design for learning objects was based on the work done from an instructivist orientation towards learning (Merrill, 1983). The emphasis in these designs was on tell, explain, practise, test, and the goal was to make that pathway as transparent as possible. More recent learning theories, based on research on the human brain (Bransford, Brown \& Cocking, 1999), focus on understanding and creating as well as knowing. They suggest that learning should be active, social, contextual (in that it links to the experiences of the learner), encourage engagement and require 
ownership. Theorists use the concept of the learning environment to describe the space where the learner uses various tools and devices to collect and interpret information through a process of interaction with others (Oliver, Harper, Hedberg, Wills \& Agostinho, 2002). As Oliver and his colleagues point out, such a learning space is flexible and iterative unlike the linear sequencing of traditional instructional design.

\subsection{Interactivity}

In constructivist learning theories, social interaction among learners is critical to the process of knowledge creation and meaning making (Duffy \& Cunningham, 1996). Such a process requires modelling, coaching and scaffolding to help learners become more aware of themselves as learners and of their metacognitive strategies. These activities help learners develop deeper understanding and therefore learning object design needs to include not only the categories of remembering, understanding, applying, analysing, evaluating and creating, identified in the latest version of Anderson and Krathwohl's (2001) version of Bloom's taxonomy, but must also include the social, contextual, motivational and ownership principles that are associated with deeper learning (McGee, 2003). McGee also argues that "interactivity is a key element not only in learning but also in the design of all technology mediated learning environments" (p. 20). She proposes that this interactivity should include not only human-human interaction but also computer adaptive learning, where the computer adapts to the learner and provides learner support during knowledge construction through metacognitive scaffolding.

\subsection{Scaffolding}

In concert with Hannifin and Hill (2002), Orrill (2001) sees learning objects as being of two kinds: as resources and as scaffolding. Resource objects "enable students easy access to information in a just-in-time fashion" (p. 10) and this can be factual or skills based. Scaffolding can be provided in three ways. First is conceptual scaffolding which focuses on key concepts needed for understanding. Second is strategic scaffolding which involves offering a variety of approaches to the concept to help develop deeper understanding. The third is metacognitive scaffolding which is concerned with reflection through self assessment. Deubel (2003) stressed the importance of scaffolding in universal design (Pisha \& Coyne, 2001). Universal design is based on Vygotsky's three conditions for involvement for learning: recognition, planning for action, and affective engagement. The influence of universal design principles on learning objects is just beginning but is likely to have increasing impact on learning objects in the $\mathrm{K}-12$ sector. 
The advantages of flexible and fade-able scaffolding were raised by Luckin (2001) in her study designed to ensure interactivity through collaboration in Vygotsky's zone of proximal development. She found in working with 10 and 11 year olds, that such scaffolding was essential since children were not effective at setting themselves challenging tasks or at seeking appropriate assistance. These aspects of appropriate scaffolding, encouraging persistence and asking challenging questions were also identified by Arthur and her colleagues (2001) in their study of effective elearning environments for young primary school children. This suggests that these aspects need to be included for learning objects to be effective.

\subsection{Cultural context}

We now realise that all learning is embedded in a cultural context, usually of the majority culture and when learning theories highlight the importance of realistic contexts and shared experiences, cultural inclusivity needs to be integral to the design. McLoughlin and Oliver (2000) refer to it as cultural localisation. They developed ten design principles for a culturally inclusive design for indigenous Australian learners and believe that use of these design principles will help promote culturally responsive learning environments. Similarly, equity issues have been responded to through the development of universal design principles to address issues of accessibility due to disability.

Particularly in countries with compulsory schooling, the choice of curriculum topics and the pedagogical orientation taken towards learning reflect the values of the society. These are transmitted through schooling in the life of the classroom. Learning objects that support alternative values may be less useful to a teacher since extensive re-purposing may be required to adapt the object for use in that country's classrooms. Another issue that is particularly a concern in the K-12 sector is the importance of all objects meeting the country's legislation concerning issues such as gender, ethnicity, vocabulary and inclusiveness. For example, school materials are not only vetted to ensure that there is no ethnic bias but they also need to be examined to ensure that they do not leave out ethnicities that are likely to be present among school children and that they avoid stereotypes that reinforce inappropriate attitudes towards others. There are similar concerns about representation and silencing for gender, inclusiveness, and religion.

\subsection{Conclusion}

Instructivist designs are created to convey information. Based on a tellexplain - practice-test linear model, they should have clarity of presentation, the laddering of knowledge, and well-designed formative 
and summative assessment. The fundamental issues in designing constructivist learning environments is that they are not about communicating knowledge but rather aid knowledge construction. Interactivity is essential. Further, the sequence for learning is not linear but more like parallel processing, involving a fluid and dynamic web of knowledge experiences that includes both concept and context rather than only nodes of concepts and related constructs. In addition, construction of new meaning implies the active involvement of the learner in making choices about what experiences to undertake. Since constructivist learning environments are more process than content oriented, Bannan-Ritland and colleagues (2003) note the importance of scaffolding to support learners in organising, restructuring or representing their knowledge through creating new objects. In particular, scaffolding can assist for example, "in organizing the information in many ways, permitting key word searches, providing learners the opportunity to contribute their own information in the form of notes, presenting various views of the content through linking relevant pictures and text notes" (p. 29). They also propose that hypermedia be included to further scaffolding conceptualisation. In the K12 sector, the designs need to be culturally appropriate and inclusive and address accessibility.

\section{Multimedia learning object design principles}

Digital multimedia theory provides for other learning environment possibilities. Norman (1993) identified seven aspects of an appropriate learning environment. These were (1) an intensity of interactivity and feedback, (2) specific goals and procedures, (3) motivation, (4) a sense of challenge that veered neither into anxiety nor boredom, (5) a sense of direct engagement that encouraged the willing suspension of disbelief in the scenario, (6) appropriate tools that neither intruded in the game or distracted from it, and (7) the avoidance of distractions or diversions that pulled the learner away from the environment.

\subsection{Simulations}

In a virtual learning environment, simulations are often considered to be the most effective way of reaching these multiple goals. Through a review of the student use of two learning environments that included both experiential and symbolic simulations, Harper, Squires and McDougall (2000) found that learners wanted more simulations with greater fidelity to real world situations and also more opportunities for symbolic manipulation. The advantage of the inclusion of greater numbers of symbolic manipulations was that they allowed students to work with highly complex realistic situations without succumbing to uncertainty, because they were able to work back and forth between the experiential 
and the symbolic. From this, they proposed that the design framework for experiential simulations should address constructivist concerns for complexity, credibility and ownership.

\subsection{Gaming}

A second virtual environment design is based on gaming. The intent of gaming is to achieve success within a virtual environment. Houser and Deloach (1993) identified seven principles for effective gaming design. They began with the "attract mode", the short free demonstration which runs on video game machines and can be accessed without putting in coins. This provides an overview of the game, a trial of the tools and the storyline, engaging the user without any actual participation. They saw this initial engagement as essential in motivation and in communicating the objective. They advised keeping instructions brief and relevant and hiding tools not essential to the main goal as ways of keeping the user focused on the game story and metaphor. Performance coaching, as distinct from merely providing information, and consistent feedback were also required as the game moved from simple to more complex situations. Foreman (2004) found that gaming simulations were most likely to be engaging to adolescent boys.

\subsection{Experiential situations}

The use of the experiential in simulations is supported by the work of Berg (2000) who proposed storytelling and narrative as an appropriate approach to interface design. Basing his work on the multiple perspectives promoted by New Wave film directors, he concluded that presenting content in narrative form increased comprehension, and suggested that instructional designers should use film narrative conventions to take advantage of an already established meaning code, and that stories should be told from multiple perspectives to ensure critical reasoning. Integral to the process, he recommended that learners should have the opportunity to re-create their own stories based on the external narrative and their own experiences.

\subsection{Multimedia combinations}

Mayer (2002) has identified "eight tentative principles of multimedia design, each based on cognitive theory and supported by empirical research" (p. 69). In designing his experiments, Mayer required students to solve a problem, or to explain why something did or did not occur. From his studies he found that students learn more deeply from a multimedia (narrated animation) presentation than from a verbal explanation alone, and that they learned more from words and pictures than from words 
alone. He found that it was best to provide the animation and narration simultaneously rather than consecutively. Extraneous words, sounds and video, peripheral to the main text, negatively affected students' attention and learning. However, having both the picture and the text on screen can overload students' sensory processing and interfere with learning. Instead, providing audio narration ensures that this is less likely and students can focus on the animation. Students given visual and auditory information performed consistently better than those receiving visual pictures and text on screen during testing. Providing all three split students' attention from the visual information and, during testing, such students did less well than those with visual and auditory information only.

\subsection{Active engagement}

In other research Moreno, Mayer, Spires and Lester (2001) found that students involved in an activity were better able to remember and transfer their learning to new situations than those who just read the material. Furthermore, when the information was presented orally, students retained more than when the information was in on screen text and student outcomes did not differentiate between a video of an actual or an animated face. Mayer (2002) also found that students did better when the information was presented in a conversational rather than expository style, and when the narrator using cues such as "first" or "then", signaled important information through changes in the voice. Finally, when learners were given more control of the rate of upcoming materials (they chose when to see the next screen), they learned more deeply. One immediate outcome of this research is that it confirms the proposals of accessibility experts who have found advantages in accompanying animated visuals with audio rather than text. Mayer's research pulls together and builds on work concerned with a number of these issues.

\subsection{Conclusion}

From our review of the literature on pedagogical and multimedia design research, we identified the following features as important in learning object design. Within the two general design formats, instructivist and constructivist designs, certain features stood out. Simulations, whether immersive environments, games or narratives, were seen as more engaging and motivational for learners. These environments should be interactive, involve a variety of media and provide a range of scaffolding supports as well as more direct performance coaching. Learners needed to be engaged immediately and to have control so as to move backwards and forwards through the learning object at will. They should also have opportunities to create new objects or materials from the work they did. Such objects needed to be culturally inclusive and accessible. Together these form a 
palette of desirable learning design features recommended for inclusion in learning objects.

\section{Method}

Our intent was to describe the pedagogical and media design features of selected learning objects developed for the K-12 sector. As part of a larger case study undertaken to make recommendations regarding the development models used by The Le@rning Federation, and the place of the Federation's work in international contexts, we had the opportunity to review a range of learning objects from their database. We did the reviews in two stages; initially 21 learning objects were chosen and then a further 14 were examined to see the extent of development after a year based on initial feedback. The 35 objects were selected by The Le@rning Federation from amongst those published at the time using the criteria of (a) K-10 spread (b) curriculum area spread (c) learning design spread (d) growth in design from 2003 to 2004 and (d) size. While the 36 objects were less than $10 \%$ of the objects under development, the size of objects, the state of trialling at the time, the diversity of designs represented, and the amount of work involved were other factors considered in deciding on the objects for examination. The content of the learning objects ranged from mathematics to music. Most of the initial 21 were focused on elementary students but we had more secondary representation in the second set. The objects are listed in Table 1 and are available for review on The Le@rning Federation website [http:/ / www.thelearningfederation.edu.au/].

Table 1: Learning objects reviewed

To view Learning Objects, see The Le@rning Federation. http: / / http: / / www.thelearningfederation.edu.au/

\begin{tabular}{|l|l|l|}
\hline Learning object title 2003 & \multicolumn{1}{|c|}{ Curricular area } & \multicolumn{1}{|c|}{ Multimedia used } \\
\hline Maths: The Array & Maths & Flash, animation \\
\hline Maths: The Array: Go Figure & Maths & Flash, animation \\
\hline $\begin{array}{l}\text { Maths: Number Partner } \\
\text { Faths: Number Partner; Go }\end{array}$ & Maths & Flash, animation \\
\hline $\begin{array}{l}\text { The Multiplier: Generate } \\
\text { Hard Multiplications }\end{array}$ & Maths & Flash, animation \\
\hline The Multiplier: Go Figure & & Flash, animation \\
\hline $\begin{array}{l}\text { The Multiplier: Make Your } \\
\text { Own Easy Multiplications }\end{array}$ & & Flash, animation \\
\hline Design Your Own Park & Maths & Flash, animation \\
\hline Design A School & Maths & Flash, animation, sound \\
\hline $\begin{array}{l}\text { Compound Shapes: } \\
\text { Complex }\end{array}$ & Maths & Flash, animation, sound \\
\hline Dynamic Fractions & Maths & Flash, animation \\
\hline
\end{tabular}




\begin{tabular}{|c|c|c|}
\hline Explore Water Pipes & Science & $\begin{array}{l}\text { Flash, animation, sound, still } \\
\text { photography }\end{array}$ \\
\hline $\begin{array}{l}\text { Where Does Tap Water } \\
\text { Come From? }\end{array}$ & Science & $\begin{array}{l}\text { Flash, animation, sound, still } \\
\text { photography }\end{array}$ \\
\hline $\begin{array}{l}\text { Where Do Frogs Lay Their } \\
\text { Eggs? }\end{array}$ & Science & $\begin{array}{l}\text { Flash, animation, sound, still } \\
\text { photography }\end{array}$ \\
\hline Caving & Science & $\begin{array}{l}\text { Flash, animation, sound, still } \\
\text { photography }\end{array}$ \\
\hline In Digestion & Science & Flash, animation, sound \\
\hline Plant Scan & Science & Flash, animation, sound, \\
\hline Mine Rescue & Science & Flash, animation, sound, \\
\hline Check Your Wind & Science & Flash, animation, sound, \\
\hline Finders Keepers & Literacy & Flash, animation, sound, \\
\hline To Catch A Thief & Literacy & Flash, animation, sound, \\
\hline Learning object title 2004 & Curricular area & Multimedia used \\
\hline $\begin{array}{l}\text { Rainforest tracks, maps and } \\
\text { signs }\end{array}$ & Literacy & $\begin{array}{l}\text { Flash, animation, sound, still } \\
\text { photography }\end{array}$ \\
\hline Sonic space: city & $\begin{array}{l}\text { Innovation, enterprise } \\
\& \text { creativity (IEC) }\end{array}$ & $\begin{array}{l}\text { Flash, animation, sound, still } \\
\text { photography }\end{array}$ \\
\hline $\begin{array}{l}\text { Lost bike : build your own } \\
\text { bike[Indonesia] }\end{array}$ & $\begin{array}{l}\text { Language other than } \\
\text { English (LOTE) }\end{array}$ & Flash, animation, sound \\
\hline $\begin{array}{l}\text { Stampede: balloon stampede } \\
\text { [Japan] }\end{array}$ & LOTE & Flash, animation \\
\hline Buds 3 & IEC & Flash, animation, sound \\
\hline Rap Machine & Literacy & Flash, animation, sound \\
\hline $\begin{array}{l}\text { Musical number patterns: } \\
\text { music maker }\end{array}$ & Maths & Flash, animation, sound \\
\hline Wishball: thousandths & Maths & Flash, animation, sound \\
\hline Wishball: whole numbers & Maths & Flash, animation, sound \\
\hline $\begin{array}{l}\text { Environmental evaluation } \\
\text { project: frog pond habitat }\end{array}$ & Science & Flash, animation, sound \\
\hline Wild ride: get a grip & Science & Flash, animation, sound \\
\hline Wild ride: race day & Science & Flash, animation, sound \\
\hline Gold Rush level 2 & Studies of Australia & $\begin{array}{l}\text { Flash, animation, sound, } \\
\text { photography, archival } \\
\text { documents }\end{array}$ \\
\hline Heroes of the Air & Studies of Australia & $\begin{array}{l}\text { Flash, animation, sound, } \\
\text { photography, video archival } \\
\text { documents }\end{array}$ \\
\hline
\end{tabular}

One point that should be mentioned is the difficulty of determining the level or age appropriateness of specific learning objects. We did not have access to the complete metadata for each object. Learning objects are designed to be reused in a variety of grade levels and for a multitude of purposes. Therefore any of the objects might be used for enrichment, for remediation, or to extend and enhance age appropriate instruction in classrooms or online. 
The agency made the learning objects available to us electronically for a restricted period. We accessed the objects, and because we live in different parts of Canada we reviewed them independently and then discussed our analyses by telephone. One advantage of electronic access was that we were immediately able to return to an object if we disagreed about an attribute. We did not have to depend on written notes. We used our discussions to inform each other about the objects and enrich our understandings of their capabilities. The objects' capabilities for enrichment versus initial learning activity or content acquisition and issues around how students might use the objects formed a large part of our discussions. Our intent in this exercise was to describe how recommended pedagogical features of learning objects were present in practical examples. We believe that this information is helpful for other curriculum designers seeking to develop learning objects for schools. We subsequently evaluated the objects using a rubric based on a combination of the CLOE draft guidelines [http://1t3.uwaterloo.ca/CLOE/], the Vargo, Nesbit, Belfer and Archambault criteria (2003), the Soundness Specifications from The Le@rning Federation, and criteria specific to the K-12 sector. That process is described elsewhere (Haughey \& Muirhead, 2005).

We both began our analyses by opening and engaging with the object, following the directions on screen and also trying to click in different places and generally test out the design. We deliberately put in incorrect responses to test scaffolding, and kept notes about the various criteria previously identified: learning design orientation, scaffolding, interactivity, cultural inclusion and accessibility, multimedia use, active engagement, simulations, narrative or experiential situations, and gaming. In the process, we added two new headings to the list: extensions which referred to activities that the student could do elsewhere, based on some aspect of the object's design, and visualisation which is an aspect of simulation whose value became very evident pedagogically as we worked through the objects. This list is not codified beyond its basis in multiple research findings and pedagogical and multimedia theories. We did not attempt to categorise the extent of presence of a category or how many times an individual attribute occurred in an object; rather we were interested in how these aspects were present and how they were used to facilitate learning in designs used by school students.

\section{Findings}

While we recognised that each learning object had its own integrity of design, we focused our analyses on the specific features which the literature recommends for digital learning objects. Our findings are reported under the heading identified earlier and with reference to specific objects. 


\subsection{Learning object designs}

We found many examples of instructivist designs. They most often employed one of two formats: direct instruction or scientific method, although some were modeled on games.

The direct instruction design involved a statement of the objective, a description of the task, opportunities for practice, and then evaluation. These designs often employed tasks such as matching or sequencing (The Array objects). A sequence of such tasks was sometimes built into objects to provide for a laddering of difficulty. Generally, the focus was on knowledge acquisition and application. In some cases students could choose to increase the level of difficulty through use of a slider-like icon. Students could also use a similar slider to decrease the time to completion and increase the challenge.

Some learning object designs followed the full scientific method of information gathering, hypothesis setting, experimentation, interpretation and conclusion while other learning objects focused on aspects of the method (Wild Ride objects; Mine Rescue object). One, for example, focused on examining and weighing evidence. Students were given lots of choice and multiple evidence sources but their results had to fit within the parameters of a preset survey which guided their activities. Some focused on illustrating a principle or testing knowledge and needed to be embedded in a classroom design to be fully effective.

A third strategy was the use of a game design. These started with a puzzle to solve or a treasure to be found. The better ones linked correct answers to information that helped students make subsequent choices (Wishball objects). The genesis for these games seemed to be board games rather than digital computer games. One of the difficulties with this design is that the features which encourage involvement in the game, such as a race against time, may not be relevant to and may interfere with what is to be learned. These designs do not often provide the opportunity to practise skills prior to involvement in the game.

Inquiry based or problem based learning designs sought to engage the learner in working with a variety of materials to achieve a goal. Examples ranged from students taking sound elements and recombining them to create a new soundscape object (Sonic Space: City), to students examining historical material in order to write their own news stories (Heroes of the Air). Problem based learning was the design particularly used in materials designed for secondary learners. Faced with a general question, students needed to do a variety of different but interrelated activities in order to be able to provide in depth responses. Students had choices about which to do 
first and could return to earlier screens to rethink issues as they worked through the object (Environmental evaluation: Frog pond habitat).

Within these design formats, designers consistently employed a variety of strategies to meet specific goals. Each strategy is dealt with in turn but in practice, they overlapped and often met more than one goal.

\subsection{Scaffolding}

Although strongly connected with constructivist approaches, providing contextualised assistance to learners is a well-recognised strategy. In terms of conceptual scaffolding (explanation of concepts), designers most often did this through specific hint buttons or the use of a hypertext link to a glossary. Some objects provided information about what learners needed to know before they began and a short review for those who chose to read it, but most left this as a statement in the accompanying teacher notes. The provision of strategic scaffolding occurred through the use of a context sensitive help button to provide alternatives. This aided the learner in moving through the exercise through specific and timely support. There were a number of examples in the Mine Rescue object.

Metacognitive scaffolding refers to scaffolding that provides for reflection through self assessment. Some objects used leading questions to encourage reflective thinking and others provided an electronic notebook for the learner to keep notes, record and reflect on observations. In terms of self assessment, many only indicated that the answer chosen was incorrect. They provided lots of opportunities for trying again without penalty but missed the opportunity to provide coaching to enhance the learner's actual performance. Scaffolding could have been used to aid students' analyses of their errors and deepen their understanding.

\subsection{Extension}

Extension refers to opportunities to extend the work done within the learning object to off line work that can be completed elsewhere. For example, some learning objects included opportunities to print the worksheet for later use or as a record, some saved the data generated by the learner into a spreadsheet that could be accessed later, and some provided notebook data separately so that it could be used in developing a report. For younger learners, some objects provided instructions for printing a page which related to the object and which could also be used as a record, such as a mining permit from a learning object on gold mining (Gold Rush 2). Another provided a page which included the drag and drop data generated by the learner and which could be used to form a jigsaw (Where does tap water come from?). The Sonic space: city object has a notebook included but it couldn't be saved and printed, while this was a 
feature for the Frog pond habitat object. The Mine Rescue object included space for a personal report which the student could then print, as well as the opportunity to record the results of their observations. These all helped provide a greater integration between the learning objects and class work.

\subsection{Cultural inclusion and accessibility}

Learning objects designed for the K-12 sector are usually vetted for cultural inclusion and these proved to be no exception. Designers had included use of items, clothing and scenery and included characters and voices from different ethnic groups which linked the objects to the students' context.

\subsection{Multimedia elements}

In terms of accessibility, the major adaptation concerned low literacy levels and many objects included voice over audio to complement text to assist such readers. For example, one object focused on understanding rather than writing and included a check box feature rather than having the student key in answers. Another provided a sliding rule for students working with multiplication of data. The Rainforest tracks maps and signs object had both audio and video instructions for low literacy learners and a reply button which gave them control over changing the screen.

\subsection{Interactivity}

The premises of interactivity are that it increases student engagement and is important for meaning making. Many of the learning object examples were highly interactive, requiring students to frequently access resources or respond on screen. In addition, there were many examples of strategic scaffolding in particular so that students were always within a click of assistance. In this way, the objects fulfilled the requirements for humanmachine interchanges very well. There were a number of matching skills objects such as the Lost Bike object. What was not specified within the objects was social engagement with other learners. This would require group participation in a common learning system so that students could correspond via notes and email, or directly through activities planning by the classroom teacher. From the limited descriptions available in the preliminary field trials (Lake, Phillips, Lowe, Cummings, Schibeci \& Miller, 2004), students in practice were often grouped around and shared computers so that off-side discussions were frequent and welcomed by most students as a useful part of their learning.

\subsection{Visualisation}

Although many aspects of multimedia might provide an obvious reason for its inclusion in learning objects, its use to inform learning has to be 
paramount. One of its most obvious benefits is in visualisation and in many instances the combined use of graphics, photographs and animation was essential to providing a clear visualisation of a task or process. It was important in delineating a sequence of complex tasks and also in showing real time changes. For example, the use of an animated scenario provided sufficient information for students to be able to proceed with success. Carefully designed, it included information about the objective, the task sequence and how to handle any difficulties. Small vignettes can be used to bring external expertise to the learning situation through video, photographs, and graphic combinations (Heroes of the Air).

In some situations, the visualisation, with the inclusion of sound, can be used to provide an immediate response to a change initiated by the learner. In one learning object, students could hear and see an immediate reaction when one word was replaced by another (Stampede: balloon stampede). There was a wide range of media employed from video and graphics plus audio, to text plus audio, to the inclusion of natural sounds to increase ambience in a simulation. One excellent example was the use of graphics and sound to illustrate how rhythms from four different instruments could be combined to make different sound patterns (Music number patterns: music maker). Using the graphic interface, students could choose individual rhythms and combine them to make different patterns which they could immediately hear. Another important visualisation is the use of interactive tools to conduct experiments (Wild Ride objects). This provides an option that is often neither available nor possible in school settings. Problem solving opportunities are maximised through this visual strategy.

\subsection{Simulation}

Using interactive tools requires learners to engage with a simulation, and simulations are one of the most powerful ways for students to become immersed in learning. Simulations, particularly gaming simulations, usually begin with a splash page or attract mode, an immersive environment which provides the objectives, the storyline, the tools that the learner can use, and a demonstration of what is aimed for. A number of the objects included such a scenario to engage the learner's interest, even if the remainder of the object was not an immersive environment (Design your own park and In Digestion objects). Few objects used this opportunity to provide a review of required prior knowledge; instead they provided context sensitive scaffolding to assist the learner during the process.

In working with simulations it is important not to clutter the screen with too many tools; they can distract the learner from the main focus of the activity. Instead, they should come into play at the time they are needed. This principle was used in a number of the objects where additional tools 
or information were shaded until needed, just in time pop up instructions appeared, or all the buttons were contained within one onscreen function (In Digestion object). Another strategy for keeping learners on task was to use leading questions that contained the directions for what to do next.

\subsection{Learner control}

Learner control is another aspect of simulations that was present in varying degrees in most objects. Most provided back and forward buttons so that learners could move in either direction and could return to earlier screens if they so chose. These buttons can also be a means to self assessment and reflection and allow students to repeat sections if they wish. Some objects included the opportunity to redo sections with different information in order to provide reinforcement of the process, or extend understanding of the concept (The Multiplier series). In some objects students could choose information options that provided for further detailed contextual learning (Where do frogs lay their eggs?).

\subsection{Experiential/narrative situations}

Narrative or story telling was used across a wide variety of learning objects. Having a character of the same age range introduce the purpose and activities, tell the storyline, or set the context was seen as motivational for students. In addition, the figure also helped provide cues to cultural inclusion. The storyline often linked the task to a real world activity. Examples include animated characters like the young girl of Asian heritage who introduced the mining learning object, thereby also setting the historical context, the radio program in Heroes of the Air and the sequence at the beginning of Rainforest tracks, maps and signs.

\section{Discussion}

Overall, we found that learning designers used a wide variety of designs. The instructivist designs focused on learning as knowledge acquisition, while the constructivist designs reflected the move to learning as transforming knowledge. While instructivist designs have their place, we believe that they provide insufficient outcomes for transformative learning; transformative learning requires that learners will not only increase their knowledge but also their understanding and will develop transferable skills such as communication, interpersonal and problem solving skills. Learning is iterative (Mayes, 1995) and this requires contextualisation of new information, application in new situations and internal reflection to clarify what did and did not occur. Together, these point to deep engagement with the material. For best practice, these need to be integral to the design of learning objects. 
The learning designs of the objects we reviewed varied from very simple single tasks appropriate for younger students, or ones that focused on a specific procedure for older students, to complex designs involving multiple tasks, usually for senior or more advanced learners. In welldesigned objects, the tasks were interrelated and necessary if the learner was to be able to meet the objective. However, this did not mean that they were all presented linearly; students usually had a choice. In general, for younger students a sequence of simple learning objects was used; the complexity of individual objects increasing with the age of the student and the sophistication of the objectives. However, designers were generally wary of including too many tasks and either confusing or boring the learner. We were interested to see that learning object templates were often repurposed effectively for different content. We observed the adoption of filmic, gaming simulations and video elements in a number of the learning objects. We expect that complex objects will include the multiple perspectives essential for critical analysis and see this as important also for younger students.

As might be expected from our findings, learning objects frequently used scaffolding strategies of support and engagement, provided learner choice, and required high interactivity. They used a variety of multimedia to encourage and sustain engagement and provided a range of required activities. In this they blended many of the characteristics that have been considered constructivist. At the same time, many objects used an underlying framework of knowledge acquisition or scientific method so that students were always aware of what was to be accomplished and the best process for completion of the activity. Some objects followed an inquiry based approach which led to more individual outcomes such as news stories, and only a few objects provided creative opportunities such as the construction of a soundscape or rhythm pattern for multiple instruments.

Interactivity has an important role in multimedia designs, but it has to go further than simply allowing a learner to choose how to navigate through an object. This requires media designs that provide opportunities for learners to do tasks or practise a procedure. The use of simulations gives learners the opportunity to undertake experiments in safety and yet see the results of their actions. They can be encouraged to examine the consequences of taking wrong as well as correct approaches, with reflection leading to a deeper understanding. Cairncross and Mannion (2001) conclude "the key is to design learning activities which cognitively engage the learner, that cause them to think about the material that is presented, what it means, its relevance, how it can be applied and in what contexts" (p. 161). 
Recently, some writers (Dunning, Rogers, Magjuka, Waite, Kropp, Gantz, Kaur, Vidali, Hunt \& Vandermolen, 2004; Jones, 2004), have suggested that with the addition of simple templates, teachers will be able to make their own objects. We agree that it is likely that teachers will be able to develop objects requiring activities such as "drag and drop," or "label the figure" or "put the items in a sequence". These activities engage students and require more from them than taking notes on the topic. However, they are likely to engage the learner for less time and to a limited extent compared to the possibilities provided by more complex learning objects. In the CELEBRATE project organised by European SchoolNet (2002-2004), many teachers made such objects for use in their classrooms. McComick and his associates (McCormick, Scrimshaw, Li \& Clifford, 2004) found, however, that individually, most designed activities to reinforce information. In contrast, they found that a team model was most conducive to producing acceptable learning objects and such teams had a combination of content expertise, classroom instruction with ICT for this age group, and software programming expertise. They concluded that the development of learning objects would only be successful and sustainable if

- sufficient teachers want to use LOs (learning objects),

- sufficient LOs are produced,

- the ones produced are the ones that are wanted, and

- the teachers are able to find and successfully use the LOs they want. (p. 157)

As outlined in The Le@rning Federation documents (TLF, undated), in the K-12 setting, learning objects that are approved for use in classrooms have to meet a high standard. Teachers and curriculum specialists expect that learning objects are well designed. They expect that learning objects are free from factual error, incorporate navigation and design features to allow their use by all students, and meet international technical standards. In addition, K-12 curriculum specialists agree that learning objects need to represent current thinking about the specific subject matter, and the national or state curriculum agency responsible for developing these learning objects emphasises instructional design principles to ensure that learning objects incorporate pedagogy that supports best teaching practices. Learning objects also need to meet national and international multimedia design standards, such as the ISO 14915 specifications for multimedia user interface design involving ergonomic requirements for human centred multimedia interfaces.

For all of these reasons, it is likely that the demand for quality assurance and for standards compliance will require national and state agencies to be involved in the provision of appropriate learning objects. This has advantages in that the agency will be able to ensure that those who design 
learning objects meet their requirements, but it also ensures that more groups and organisations are made aware of what these are. Over time, the numbers of groups able to develop objects will be enhanced through this capacity building.

The emergence of learning objects as a focus of educational interest is relatively recent and much of the discussion has not been based on the actual development and use of objects. This research goes somewhat to address this issue in that the work has involved the analysis of actual objects, but it is still missing research on actual use. The field trials (Lake, Phillips, Lowe, Cummings, Schibeci \& Miller, 2004) of these learning objects showed that when used appropriately teachers and students were excited about their possibilities; however, other teachers were not yet at the stage, for infrastructure or professional development reasons, of being able to design classroom lessons which integrated use of learning objects. That is the area where we need to focus next.

We recommend continuing research on the integration of multimedia and pedagogical design in learning objects. We need studies on the design affordances of particular learning objects, whether a scientific method design or an inquiry based learning object with multiple activities is equally effective, and we need studies about how the multiple stakeholders for learning object development in the K-12 sector resolve their issues (Hedberg, 2004). We also need studies that integrate design and use. For example, in a field trial (Lake et al., 2004), researchers found that students knew to put in any keyboard character when an answer was required rather than trying to provide a correct response. Their need for an immediate response was greater than that for achievement. Also required are studies that examine how teachers integrate learning objects into classroom activities. All three kinds of studies will have implications for improving the design of learning objects for schools.

\section{References}

Anderson, L. \& Krathwohl, D. (Eds) (2001). A taxonomy for learning, teaching and assessing. New York: Longman.

Arthur, L., Beecher, B. \& Downes, T. (2001). Effective learning environments for young children using digital resources: An Australian perspective. Information Technology in Childhood Education Annual 2001(1), 139-153.

Bannan-Ritland, B., Dabbagh, N. \& Murphy, K. (2000). Learning object systems as constructivist learning environments: Related assumptions, theories, and applications. In D. A. Wiley (Ed), The Instructional Use of Learning Objects: Online Version. [viewed 12 Sep 2003, verified 30 Oct 2005]

http: / / reusability.org/read/ chapters/bannan-ritland.doc 
Berg, G. (2000). Cognitive development through narrative: Computer interface design for educational purposes. Journal of Educational Multimedia and Hypermedia, 9(1), 3-17.

Bransford, J.D., Brown, A.L. \& Cocking, R.R. (Eds) (1999). How people learn: Brain, mind, experience and school. Washington, DC: National Academy Press. [verified 30 Oct 2005] http:/ / books.nap.edu/html/howpeople1/

Cairncross, S. \& Mannion, M. (2001). Interactive multimedia and learning: Realizing the benefits. Innovations in Education and Teaching International, 38(2), 156-164.

Deubel, P. (2003).An investigation of behaviorist and cognitive approaches to instructional media design. Journal of Educational Multimedia and Hypermedia, $12(1), 63-90$.

Duffy, T. M. \& Cunningham, D. J. (1996). Constructivism: Implications for the design and delivery of instruction. In D.M. Jonassen (Ed), Handbook of research for educational communications and technology (pp. 170-198). London: PrenticeHall.

Dunning, J., Rogers, R., Magjuka, R., Waite, D., Kropp, K., Gantz, T., Kaur, A., Vidali, A., Hunt, T. \& Vandermolen, L. (2004). Technology is too important to leave to technologists. Journal of Asynchronous Learning Networks, 8(3), 11-21. http: / / www.sloan-c.org/publications/jaln/v8n3/v8n3_dunning.asp

Hannafin, M. \& Hill, J. (2002). Epistemology and the design of learning environments. In R. A. Reiser \& J.V. Dempsey (Eds), Trends and issues in instructional design and technology (pp. 70-82). New York: Prentice-Hall.

Harper, B., Squires, D. \& McDougall, A. (2000). Constructivist simulations: A new design paradigm. Journal of Educational Multimedia and Hypermedia, 9(2), 115-130.

Haughey, M. \& Muirhead, B. (2005). Evaluating learning objects for schools. EJournal of Instructional Science and Technology, 8(1). http:/ / www.usq.edu.au/electpub/ejist/docs/vol8_no1/fullpapers/eval_learnobjects_school.htm

Hedberg, J. (2004). Designing multimedia: Seven discourses. Cambridge Journal of Education, 34(2), 241-256.

Houser, R. \& Deloach, S. (1998). Learning from games. Seven principles for effective design. Technical Communications Online, 45(3), 319-330.

Jones, R. (2004). Designing adaptable learning resources with learning object patterns. Journal of Digital Information, 6(1), Article 305, 2004-12-10. [viewed 31 Dec 2004 at http: / / jodi.ecs.soton.ac.uk/Articles/v06/i01/Jones/?printable=1, verified 30 Oct 2005 at http:/ / jodi.tamu.edu/Articles/v06/i01/Jones/]

Lajoie, S. P. (2003). Enhancing learning and teaching with emergent technologies. Keynote presentation, ED-MEDIA 2003 Conference, Thursday June 26. Honolulu, HI. [verified 30 Oct 2005]

http: / / www.aace.org/conf/edmedia/speakers/lajoie.htm 
Lake, D., Phillips, R., Lowe, K., Cummings, R., Schibeci, R. \& Miller E. (2004). Field review of the Schools Online Curriculum Content Initiative. Report of Stage 1. Melbourne: The Le@rning Federation. [verified 30 Oct 2005]

http:/ / www.thelearningfederation.edu.au/tlf2/sitefiles/assets/docs/brochures_reports / research/tlfwa_report_final.pdf

Luckin, R. (2001). Designing children's software to ensure productive interactivity through collaboration in the zone of proximal development (ZPD). Information Technology in Childhood Education Annual 2001(1), 57-85.

Mayer, R. (2002). Cognitive theory and the design of multimedia instruction: An example of the two-way street between cognition and instruction. New Directions for Teaching and Learning, 89, 55-71.

Mayes, J. T. (1995). Learning technology and Groundhog Day. In W. Strang, V. Simpson \& D. Slater (Eds), Hypermedia at work: Practice and theory in education. Canterbury, UK: University of Kent Press.

McCormick, R., Scrimshaw, P., Li, N. \& Clifford, C. (2004). CELEBRATE Evaluation report (version 2). [viewed $5 \mathrm{Dec} 2004$, verified 30 Oct 2005] http: / / www.eun.org/eun.org2/eun/Include_to_content/celebrate/file/Delive rable7_2EvaluationReport02Dec04.pdf

McGee, P. (2003). Learning objects: Bloom's taxonomy and deeper learning principles. Accepted for presentation at the E-Learn Conference, Phoenix, AZ (7-11 Nov). [viewed 12 Sep 2003, verified 30 Oct 2005] http: / / educ3.utsa.edu/pmcgee/nlii/McGee_eLEARN_2003.doc

McGreal, R. (2004). Learning objects: A practical definition. International Journal of Instructional Technology and Distance Learning, 1(9). [viewed 4 Dec 2004, verified 30 Oct 2005] http: / / itdl.org/Journal/Sep_04/article02.htm

McLoughlin, C. \& Oliver, R. (2000). Designing learning environments for cultural inclusivity: A case study of indigenous online learning at tertiary level. Australian Journal of Educational Technology, 16(1), 58-72. http: / / www.ascilite.org.au/ajet/ ajet16/mcloughlin.html

Merrill, D. (2002). Position statement and questions on learning objects research and practice. Paper presented at panel, Learning objects technology: Implications for educational research and practice, AERA, 1-5 April, New Orleans, LA. [viewed 12 Sep 2003, verified 30 Oct 2005]

http: / / www.learndev.org/LearningObjectsAERA2002.html

Merrill, M.D. (1983). Component display theory. In C. Reigeluth (Ed), Instructional design theories and models (pp. 282-333). Hillsdale, NJ: Erlbaum Associates.

Moreno, R., Mayer, R., Spires, H. \& Lester, J. (2001). The case for social agency in computer-based teaching: Do students learn more deeply when they interact with animated pedagogical agents? Cognition and Instruction, 19(2), 177-213. 
Norman, D. (1993). Things that make us smart: Defending human attributes in the age of the machine. New York: Addison Wesley.

Oliver, R., Harper, B., Hedberg, J., Wills, S. \& Agostinho, S. (2002). Formalising the description of learning designs. In A. Goody, J. Herrington \& M. Northcote (Eds), Quality conversations: Research and Development in Higher Education, Volume 25 (pp. 496-504). Jamison, ACT: HERDSA. [verified 30 Oct 2005] http: / / www.ecu.edu.au/conferences/herdsa/main/ papers/ref/pdf/Oliver.pdf

Orrill, C. H. (2001). Learning objects to support inquiry-based, online learning. In D. A. Wiley (Ed), The Instructional Use of Learning Objects: Online Version. [viewed 12 Sep 2003, verified 30 Oct 2005] http: / / reusability.org/read/ chapters/orrill.doc

Pisha, B. \& Coyne, P. (2001). Smart from the start: The promise of universal design for learning. Remedial and Special Education, 22(4), 197-203.

TLF (The Le@rning Federation) (undated). TLF documents. http: / / www.thelearningfederation.edu.au/tlf2/ showMe.asp?nodeID=3

Vargo, J., Nesbit, J. C., Belfer, K. \& Archambault, A. (2003). Learning object evaluation: Computer mediated collaboration and inter-rater reliability. International Journal of Computers and Applications, 25 (3), 198-205.

Wiley, D. (2000). Connecting learning objects to instructional design theory: A definition, a metaphor, and a taxonomy. In D.A. Wiley (Ed), The instructional use of learning objects Online version (Chapter 1). [viewed 12 Sep 2003, verified 30 Oct 2005] http: / / reusability.org/read/ chapters/ wiley.doc

Dr Margaret Haughey, Professor, Education Policy Studies, and Associate Dean, Faculty of Graduate Studies and Research, 7-113, Education N,

Edmonton, AB, Canada T6G 2G5. Email: haughey@ualberta.ca

Bill Muirhead, Associate Provost, Teaching and Learning, Office of the

Provost, University of Ontario Institute of Technology, 2000 Simcoe Street

North, Oshawa, Ontario, Canada L1H 7K4. Email: Bill.Muirhead@uoit.ca 